\title{
Does the Conjunctivochalasis Accompanied by Pseudoexfoliation Syndrome Affect the Ocular Surface and Anterior Segment Structures?
}

Bediz Özen ( $\sim$ bedizozen@yahoo.com )

Izmir Tepecik Training and Research Hospital, Izmir, Turkey https://orcid.org/0000-0001-9020-3810

\section{Hakan Öztürk}

Izmir Tepecik Training and Research Hospital Izmir II Saglik Mudurlugu Izmir Saglik Bilimleri Universitesi Tepecik Egitim ve Arastirma Hastanesi

\section{Research Article}

Keywords: Anterior segment, Conjunctivochalasis, Ocular surface, Pseudoexfoliation, Total conjunctivochalasis score.

Posted Date: January 10th, 2022

DOl: https://doi.org/10.21203/rs.3.rs-1178470/v1

License: (9) (1) This work is licensed under a Creative Commons Attribution 4.0 International License. Read Full License 


\section{Abstract}

Purpose: Probability of coexistence of conjunctivochalasis and pseudoexfoliation syndrome (PES) in same individual may increase with aging. We investigated effects of conjunctivochalasis accompanied by PES on ocular surface (OS) and anterior segment (AS) structures.

Methods: Cases with only conjunctivochalasis were determined as group-1 $(n=62)$, cases with conjunctivochalasis accompanied by PES as group- $2(n=45)$, and healthy cases as group-3 $(n=56)$. OS and AS parameters of groups were compared.

Results: Compared to group-1, group-2 had higher grade-3 conjunctivochalasis $(17.7 \%$ vs $46.7 \%, p=0.039)$, greater mean grade of conjunctivochalasis (MGC) $(1.72 \pm 0.24$ vs $2.29 \pm 0.32, p=0.036)$, higher total conjunctivochalasis score (TCS) $(4.27 \pm 1.13$ vs $6.12 \pm 1.35, p=0.025)$, shorter tear-film break-up time (TBUT) (9.17 \pm 2.53 vs $5.41 \pm 1.32, p=0.010)$, greater OS disease index (OSDI)-score ( $16.28 \pm 3.15$ vs $27.36 \pm 4.12, p=0.037)$. Compared to group-3, both group-1 and group-2 had shorter TBUT (group 3-1: $p=0.004$; group 3-2: $p<0.001$ ) and greater OSDI score (group 3-1: $p=0.042$; group 3-2: $p=0.019$ ). Schirmer tests, central corneal thicknesses, keratometries, axial lengths, anterior chamber depths and lens thicknesses of groups were similar ( $p>0.05)$. In group-1 and group-2, as age increased, both MGC ( $r=0.349, p=0.043 ; r=0.403, p=0.022$, respectively $)$ and TCS $(r=0.322, p=0.046 ; r=0.372, p=0.031)$ increased. In group -2 , as both MGC and TCS increased, TBUT $(r=-0.370$, $p=0.034 ; r=-0.401, p=0.025)$ decreased and OSDI score $(r=0.338, p=0.045 ; r=0.362, p=0.040)$ increased.

Conclusions: To our knowledge, this was the first study comprehensively investigating effects of conjunctivochalasis accompanied by PES on OS and AS structures together. We found that conjunctivochalasis might cause OS disease, while presence of PES in conjunctivochalasis cases might worsen OS disease and conjunctivochalasis findings.

\section{Introduction}

Conjunctivochalasis is described as a redundant, loose and nonedematous conjunctival folds most typically located in the inferior bulbar conjunctiva [1]. Bulbar conjunctiva is a tissue rich in collagen and elastic fibers. Elastic fibers are one of the main components of the extracellular matrix, and they provide the elasticity of tissues [2]. Aging and mechanical friction were thought to cause overexpression of matrix metalloproteinases by increasing the inflammatory cytokines, and thus to disrupt the structure of the fibrillin molecule [1-4]. Under the influence of these factors, elastic fiber degeneration and collagenolysis in bulbar conjunctiva may occur [1, 3, 57]. As a result, the adhesion of bulbar conjunctiva to the eye may be impaired, and conjunctival folds may develop [2].

Pseudoexfoliation syndrome (PES) is a disease characterized by the excessive synthesis and accumulation of white-colored abnormal elastic fibrillar material in intraocular and extraocular tissues [8, 9]. In the etiopathogenesis of PES, aging and oxidative damage were thought to disrupt the balance between matrix metalloproteinases and matrix metalloproteinase inhibitors by increasing the inflammatory cytokines, and thus to cause the abnormal elastic microfibril synthesis [10-14]. Consequently, abnormal elastic fibrillar material may accumulate in ocular structures such as conjunctiva, corneal endothelium, pupillary margin, anterior lens capsule and/or zonular fibers [8, 9]. In literature, the prevalences of conjunctivochalasis and PES were reported 
to increase with aging [15-17]. Additionally, the etiopathogenesis of conjunctivochalasis and PES appears to be similar. Therefore, the probability of the coexistence of these two diseases in the same individual may increase with aging, and it is reasonable to assess the condition of the eye in cases with both conjunctivochalasis and PES. To our knowledge, this was the first study comprehensively investigating the effects of conjunctivochalasis accompanied by PES on ocular surface (OS) and anterior segment structures together. Correlations between clinical characteristics with the mean grade of conjunctivochalasis (MGC) and the total conjunctivochalasis score (TCS) were also evaluated in this study.

\section{Methods}

This comparative and cross-sectional study was done with approval of Izmir Tepecik Training and Research Hospital's Medical Research Ethical Committee (approval number: 2020/10-10) and in line with the ethical principles of the Declaration of Helsinki. Detailed information about the study was given to all individuals, and the risks were explained. Written consent forms were received from all participants.

The diagnosis of conjunctivochalasis was made with the presence of redundant conjunctival folds on slit-lamp examination. The pseudoexfoliation material accumulation on ocular structures such as anterior lens capsule, iris surface or pupillary margin was evaluated in detail by slit-lamp examination and gonioscopy. The cases having 1) pseudoexfoliation material accumulation, 2) normal optic disc head, 3) intraocular pressure (IOP) less than $22 \mathrm{mmHg}$, and 4) normal visual field were defined as PES [18]. Cases with only conjunctivochalasis were determined as group-1 $(n=62)$, while cases with conjunctivochalasis accompanied by PES were determined as group-2 ( $n=45)$. In the similar age range with group-1 and group-2, 56 healthy individuals without any ocular and systemic disease were determined as group-3. Cases having ocular trauma or surgery, individuals who had previously been followed up and treated for dry eye, contact lens wearers, and individuals having chronic ocular disease and/or systemic disease capable of affecting the ocular structures other than the conjunctivochalasis, pseudoexfoliation or lens opacity were not included.

The personal and family histories, age and gender characteristics of all individuals were recorded. The best corrected visual acuity (BCVA) was detected by the Snellen chart. Detailed anterior and posterior segment examinations were done with a slit-lamp biomicroscope and Goldmann three-mirror lens. IOP was measured by a Goldmann applanation tonometer. The visual field examination was made with the Humphrey Field Analyzer (Zeiss Humphrey Instruments, USA). Modified Meller and Tseng's grading system was used in the grading of the conjunctivochalasis [5]. TCS was determined according to the system used by Mimura et al [19, 20]. In this grading and scoring system (Figure 1), the number of conjunctival folds and relationship to the tear meniscus height [grade (0): no persistent fold, grade (1): single, small fold, grade (2): two or more folds and not higher than the tear meniscus, grade (3): multipl folds and higher than the tear meniscus], the location of conjunctival folds $[(\mathrm{N})$ : nasal part of the lower lid, $(\mathrm{T})$ : temporal part of the lower lid, and $(\mathrm{M})$ : middle part of the lower lid (or inferior to the limbus)], the extent (E) of conjunctival folds [E (0): none, $E(1)$ : at one location, $E(2)$ : at two locations, E (3): affecting the whole eyelid], the changes provoked with downward gaze (DG) [DG (0): no difference, DG (1): height or extent of conjunctivochalasis increases], the changes provoked with digital pressure (DP) [DP (0): no difference, DP (1): height or extent of conjunctivochalasis increases], and the presence of superficial punctate staining (SPS) at the lower eyelid margin [SPS (0): absent, SPS (1): present] were evaluated $[5,19,20]$. TCS of the cases was scored between 0-9 [19]. 
Tear-film break-up time (TBUT) and Schirmer test with topical anesthesia were used for the ocular surface evaluation. In TBUT test, the fluorescein strip (Fluorescein paper, Haag-Streit AG, Switzerland) was moistened with saline solution, and it was touched to the lower fornix. Individuals were told to keep the eyes open until the first dry spots were seen on the tear film under the illumination with cobalt blue light. Time interval between the last blinking and the appearance of the first dry spots was measured. At the same time, the presence of the superficial punctate staining were assessed. In Schirmer test with topical anesthesia, proparacaine $\mathrm{HCl} 0.5 \%$ (Alcain; Alcon Company, Belgium) was dropped, followed by the five minute wait. The Schirmer test paper (SNO strips, Laboratory Chauvin, France) was placed on 1/3 outer edge of the lower eyelid. After five minutes, the amount of wetting on the paper was measured. The presence, frequency and severity of the dry eye symptoms were detected by the OS disease index (OSDI) questionnaire [21]. Central corneal thickness (CCT), keratometry, axial length (AL), anterior chamber depth (ACD) and lens thickness (LT) were determined by the optical biometry device (LenStar LS900, Haag-Streit Diagnostic, Switzerland). Only one eye of each individual was included in the study. If both eyes were suitable for the study, the eye with severe findings was selected. If the findings of both eyes were equal, one eye was chosen at random. All measurements were performed by the same masked researcher between 10.00-12.00 a.m. The average value of three measurements was recorded. Ages, genders, distributions of conjunctivochalasis grades, distributions of conjunctivochalasis locations, MGC values, TCSs, TBUTs, Schirmer test values, OSDI scores, CCTs, keratometry values, ALs, ACDs, LTs and IOPs of the groups were compared. Correlations between clinical characteristics with the MGC and the TCS were also investigated in group-1 and group-2.

Statistical Package for Social Sciences (SPSS 20.0; IBM, USA) software was used for the statistical data analysis. Before beginning this study, a post hoc power analysis was done, and it was determined that the number of sample size was 20 to identify a statistically significant difference among the main variables, with $80 \%$ statistical power and an alpha error of 0.05 . Continuous variables were expressed as mean \pm standard deviation (minimum-maximum) values, while count data were given as case number and percentage. The Kolmogorov-Smirnov test was used to determine whether the variables complied with normal distribution in the groups. The comparisons of the groups were made by the Chi-square test, Mann-Whitney $U$ test and one-way analysis of variance (ANOVA) with post hoc tests. In group-1 and group-2, the relationships between clinical characteristics with the MGC and the TCS were evaluated by the Pearson correlation analysis. $\mathrm{P}<0.05$ was considered statistically significant.

\section{Results}

The BCVAs of all cases were 20/20. Biomicroscopic fundus examinations of all individuals were normal. PES was detected in $42.1 \%$ (45/107) of all conjunctivochalasis cases. Age and gender distributions of the groups were similar ( $p>0.05)$. In group-1, grade-1 conjunctivochalasis was significantly seen more frequently than grade-3 conjunctivochalasis $(45.2 \%$ vs $17.7 \%, p=0.041)$. On the other hand, in group- 2 , grade-3 conjunctivochalasis was significantly found more frequently than grade- 1 conjunctivochalasis (46.7\% vs $17.8 \%$, $\mathrm{p}=0.040)$. Compared to group-1, group-2 had significantly lower grade- 1 conjunctivochalasis rate ( $45.2 \%$ vs $17.8 \%, p=0.042)$ and higher grade-3 conjunctivochalasis rate $(17.7 \%$ vs $46.7 \%, p=0.039)$. In intragroup comparison, the distribution of conjunctivochalasis locations was similar in both group-1 and group-2 ( $p>0.05$ ). Additionally, nasal, temporal and middle conjunctivochalasis location rates of group-1 were similar to those of group-2 ( $p>0.05)$. Compared to group-1, group-2 had significantly greater MGC (1.72 \pm 0.24 vs $2.29 \pm 0.32$, 
$\mathrm{p}=0.036)$ and higher TCS $(4.27 \pm 1.13$ vs $6.12 \pm 1.35, \mathrm{p}=0.025)$. Conjunctivochalasis characteristics of the group -1 and group-2 were given in Table 1 . 
Table 1

Conjunctivochalasis characteristics of the group-1 and group-2.

\begin{tabular}{|c|c|c|c|c|}
\hline \multicolumn{2}{|c|}{ Conjunctivochalasis characteristics } & $\begin{array}{l}\text { Cases with only } \\
\text { conjunctivochalasis } \\
\text { (Group-1, } n=62 \text { ) }\end{array}$ & $\begin{array}{l}\text { Cases with } \\
\text { conjunctivochalasis } \\
\text { accompanied by PES } \\
\text { (Group-2, } n=45 \text { ) }\end{array}$ & $\begin{array}{l}P \text { value for } \\
\text { intergroup } \\
\text { comparison }\end{array}$ \\
\hline \multirow{8}{*}{$\begin{array}{l}\text { Distribution of } \\
\text { conjunctivochalasis } \\
\text { grades } \\
(n, \%)\end{array}$} & & \multirow{2}{*}{$\begin{array}{l}\text { P value for } \\
\text { intragroup } \\
\text { comparison of } \\
\text { group-1 }\end{array}$} & \multicolumn{2}{|l|}{$\begin{array}{l}\mathrm{P} \text { value for intragroup } \\
\text { comparison of group-2 }\end{array}$} \\
\hline & & & \multicolumn{2}{|l|}{ Grade 1-2: 0.189} \\
\hline & & Grade 1-2: 0.627 & \multicolumn{2}{|l|}{ Grade 1-3: 0.040} \\
\hline & & Grade 1-3: 0.041 & \multicolumn{2}{|l|}{ Grade 2-3: 0.503} \\
\hline & & \multicolumn{3}{|l|}{ Grade 2-3: 0.138} \\
\hline & Grade-1 & $28(45.2 \%)$ & $8(17.8 \%)$ & 0.042 \\
\hline & Grade-2 & $23(37.1 \%)$ & $16(35.5 \%)$ & 0.908 \\
\hline & Grade-3 & $11(17.7 \%)$ & $21(46.7 \%)$ & 0.039 \\
\hline \multirow{7}{*}{$\begin{array}{l}\text { Distribution of } \\
\text { conjunctivochalasis } \\
\text { locations } \\
(n, \%)\end{array}$} & & $\begin{array}{l}\text { P value for } \\
\text { intragroup } \\
\text { comparison of } \\
\text { group-1 }\end{array}$ & \multicolumn{2}{|l|}{$\begin{array}{l}\text { P value for intragroup } \\
\text { comparison of group- } 2\end{array}$} \\
\hline & & N-T: 0.224 & \multicolumn{2}{|l|}{ N-M: 0.698} \\
\hline & & N-M: 0.797 & \multicolumn{2}{|l|}{ T-M: 0.385} \\
\hline & & \multicolumn{3}{|l|}{ T-M: 0.142} \\
\hline & Nasal (N) & $18(29.0 \%)$ & $15(33.3 \%)$ & 0.781 \\
\hline & Temporal (T) & $28(45.2 \%)$ & $18(40.0 \%)$ & 0.756 \\
\hline & $\begin{array}{l}\text { Middle (or } \\
\text { inferior to the } \\
\text { limbus) (M) }\end{array}$ & $16(25.8 \%)$ & $12(26.7 \%)$ & 0.937 \\
\hline \multicolumn{2}{|c|}{$\begin{array}{l}\text { Mean grade of conjunctivochalasis } \\
(M G C)\end{array}$} & $1.72 \pm 0.24$ & $2.29 \pm 0.32$ & 0.036 \\
\hline$(0-3)$ & & $(1-3)$ & \multicolumn{2}{|l|}{$(1-3)$} \\
\hline
\end{tabular}

Descriptive characteristics were expressed as mean \pm standard deviation (minimum-maximum) values.

PES: Pseudoexfoliation syndrome, $\mathrm{n}$ : Number of cases

Mann-Whitney $\mathrm{U}$ test for MGC and TCS, and Chi-square test for others, $\mathrm{p}<0.05$ statistically significant. 


\begin{tabular}{|lllc|}
\hline Conjunctivochalasis characteristics & $\begin{array}{l}\text { Cases with only } \\
\text { conjunctivochalasis } \\
\text { (Group-1, } \mathrm{n}=62)\end{array}$ & $\begin{array}{l}\text { Cases with } \\
\text { conjunctivochalasis } \\
\text { accompanied by PES } \\
\text { (Group-2, } \mathrm{n}=45)\end{array}$ & $\begin{array}{l}\text { P value for } \\
\text { intergroup } \\
\text { comparison }\end{array}$ \\
\hline $\begin{array}{l}\text { Total conjunctivochalasis score } \\
(\mathrm{TCS})\end{array}$ & $4.27 \pm 1.13$ & $6.12 \pm 1.35$ & 0.025 \\
$(0-9)$ & $(2-8)$ & $(2-9)$ & \\
\hline Descriptive characteristics were expressed as mean \pm standard deviation (minimum-maximum) values. \\
\hline PES: Pseudoexfoliation syndrome, $\mathrm{n}$ : Number of cases \\
\hline Mann-Whitney U test for MGC and TCS, and Chi-square test for others, $\mathrm{p}<0.05$ statistically significant. \\
\hline
\end{tabular}

Compared to group-1, group-2 had significantly shorter TBUT ( $9.17 \pm 2.53$ vs $5.41 \pm 1.32$ seconds, $p=0.010$ ) and greater OSDI score ( $16.28 \pm 3.15$ vs $27.36 \pm 4.12, p=0.037)$. Compared to healthy cases (group-3), both group-1 and group-2 had significantly shorter TBUT ( $14.23 \pm 3.52$ vs $9.17 \pm 2.53$ seconds, $p=0.004$ for group 3-1 comparison; $14.23 \pm 3.52$ vs $5.41 \pm 1.32$ seconds, $p<0.001$ for group $3-2$ comparison) and greater OSDI score (7.46 \pm 3.07 vs $16.28 \pm 3.15, p=0.042$ for group $3-1$ comparison; $7.46 \pm 3.07$ vs $27.36 \pm 4.12, p=0.019$ for group $3-2$ comparison). Schirmer test values, CCTs, keratometry values, ALs, ACDs, LTs and IOPs were similar in all groups $(p>0.05)$. Clinical and ocular parameters of the groups were given in Table 2. In group-1 and group-2, as age increased, both MGC ( $r=0.349, p=0.043$ for group- $1 ; r=0.403, p=0.022$ for group- 2$)$ and TCS $(r=0.322, p=0.046$ for group- $1 ; r=0.372, p=0.031$ for group-2) increased. Additionally, in group-2, as both MGC and TCS increased, TBUT $(r=-0.370, p=0.034 ; r=-0.401, p=0.025$, respectively) decreased and OSDI score $(r=0.338, p=0.045 ; r=0.362$, $p=0.040$, respectively) increased. On the other hand, in group- 1 and group-2, Schirmer test value, CCT, keratometry value, AL, ACD, LT and IOP were not significantly correlated with MGC and TCS ( $p>0.05)$. Correlations between clinical characteristics with the MGC and the TCS for group- 1 and group- 2 were given in Table 3 and Table 4. 
Table 2

Clinical and ocular parameters of the groups.

\begin{tabular}{|c|c|c|c|c|c|c|}
\hline \multirow[t]{3}{*}{$\begin{array}{l}\text { Clinical } \\
\text { characteristics }\end{array}$} & \multirow[t]{3}{*}{$\begin{array}{l}\text { Cases with only } \\
\text { conjunctivochalasis } \\
\text { (Group-1, } n=62 \text { ) }\end{array}$} & \multirow{3}{*}{$\begin{array}{l}\text { Cases with } \\
\text { conjunctivochalasis } \\
\text { accompanied by } \\
\text { PES (Group-2, } \\
n=45 \text { ) }\end{array}$} & \multirow[t]{3}{*}{$\begin{array}{l}\text { Healthy } \\
\text { cases (Group- } \\
3, n=56 \text { ) }\end{array}$} & \multicolumn{3}{|c|}{$\begin{array}{l}\text { Two-way comparisons } \\
\text { p value }\end{array}$} \\
\hline & & & & \multirow{2}{*}{$\begin{array}{l}\text { Group } \\
1-2\end{array}$} & \multirow{2}{*}{$\begin{array}{l}\text { Group } \\
1-3\end{array}$} & \multirow{2}{*}{$\begin{array}{l}\text { Group } \\
2-3\end{array}$} \\
\hline & & & & & & \\
\hline $\begin{array}{l}\text { Gender } \\
\text { (Male/Female) }\end{array}$ & $33 / 29$ & $23 / 22$ & $27 / 29$ & 0.798 & 0.612 & 0.764 \\
\hline \multirow{2}{*}{$\begin{array}{l}\text { Age } \\
\text { (year) }\end{array}$} & $64.6 \pm 3.8$ & $66.2 \pm 3.9$ & $63.8 \pm 3.2$ & \multirow[t]{2}{*}{0.589} & \multirow[t]{2}{*}{0.654} & \multirow[t]{2}{*}{0.501} \\
\hline & $(54-85)$ & $(53-85)$ & $(53-84)$ & & & \\
\hline \multirow{2}{*}{$\begin{array}{l}\text { TBUT } \\
\text { (second) }\end{array}$} & $9.17 \pm 2.53$ & $5.41 \pm 1.32$ & $14.23 \pm 3.52$ & \multirow[t]{2}{*}{0.010} & \multirow[t]{2}{*}{0.004} & \multirow[t]{2}{*}{$<0.001$} \\
\hline & $(6-14)$ & $(3-10)$ & $(9-18)$ & & & \\
\hline \multirow{2}{*}{$\begin{array}{l}\text { Schirmer test } \\
(\mathrm{mm})\end{array}$} & $12.65 \pm 2.24$ & $12.81 \pm 3.32$ & $13.37 \pm 3.65$ & \multirow[t]{2}{*}{0.892} & \multirow[t]{2}{*}{0.539} & \multirow[t]{2}{*}{0.614} \\
\hline & $(8-16)$ & $(8-17)$ & $(9-19)$ & & & \\
\hline \multirow{2}{*}{$\begin{array}{l}\text { OSDI score } \\
(0-100)\end{array}$} & $16.28 \pm 3.15$ & $27.36 \pm 4.12$ & $7.46 \pm 3.07$ & \multirow[t]{2}{*}{0.037} & \multirow[t]{2}{*}{0.042} & \multirow[t]{2}{*}{0.019} \\
\hline & $(13-21)$ & $(23-32)$ & $(3-11)$ & & & \\
\hline \multirow{2}{*}{$\begin{array}{l}\text { СCT } \\
(\mu \mathrm{m})\end{array}$} & $546.41 \pm 26.14$ & $544.38 \pm 17.43$ & $547.22 \pm 23.36$ & \multirow[t]{2}{*}{0.721} & \multirow[t]{2}{*}{0.806} & \multirow[t]{2}{*}{0.434} \\
\hline & $(512-579)$ & $(515-572)$ & $(510-578)$ & & & \\
\hline \multirow{2}{*}{$\begin{array}{l}\text { Keratometry } \\
\text { (diopter) }\end{array}$} & $41.55 \pm 1.30$ & $41.62 \pm 1.40$ & $41.58 \pm 1.20$ & \multirow[t]{2}{*}{0.526} & \multirow[t]{2}{*}{0.892} & \multirow[t]{2}{*}{0.835} \\
\hline & $(40.00-43.25)$ & $(40.00-43.50)$ & $(40.00-43.50)$ & & & \\
\hline Axial length & $22.43 \pm 0.32$ & $22.62 \pm 0.27$ & $22.74 \pm 0.41$ & 0.462 & 0.318 & 0.684 \\
\hline$(\mathrm{mm})$ & $(22.06-22.87)$ & $(22.24-22.95)$ & $(22.23-23.20)$ & & & \\
\hline Anterior & $3.38 \pm 0.12$ & $3.37 \pm 0.13$ & $3.40 \pm 0.15$ & 0.764 & 0.627 & 0.512 \\
\hline depth (mm) & (3.24-3.63) & (3.20-3.58) & $(3.21-3.66)$ & & & \\
\hline Lens thickness & $3.27 \pm 0.15$ & $3.24 \pm 0.12$ & $3.26 \pm 0.13$ & 0.563 & 0.789 & 0.645 \\
\hline$(\mathrm{mm})$ & $(3.04-3.50)$ & $(3.05-3.42)$ & (3.07-3.43) & & & \\
\hline Intraocular & $13.8 \pm 2.1$ & $14.3 \pm 1.7$ & $14.1 \pm 2.5$ & 0.572 & 0.683 & 0.774 \\
\hline$(\mathrm{mmHg})$ & $(10-17)$ & $(11-18)$ & $(10-18)$ & & & \\
\hline Descriptive cha & teristics were exprecs & Las mean + standard & Jeviation (minim & $m-m a x i$ & um) vals r r r & es. \\
\hline $\begin{array}{l}\text { PES: Pseudoexf } \\
\text { disease index, } C\end{array}$ & ation syndrome, n: N & $\begin{array}{l}\text { nber of cases, TBUT: } \\
\text { hess. }\end{array}$ & ar-film break-u| & $\mathrm{me}, \mathrm{Os}$ & Ocula & urface \\
\hline $\begin{array}{l}\text { Chi-square tes } \\
\text { statistically sic }\end{array}$ & $\begin{array}{l}\text { gender, and one-wa } \\
\text { ant. }\end{array}$ & alysis of variance $(A$ & JVA) with pos & c test & & $=0.05$ \\
\hline
\end{tabular}


Table 3

Correlations between clinical characteristics with the mean grade of conjunctivochalasis and the total conjunctivochalasis score in group-1.

\begin{tabular}{|lllll|}
\hline & \multicolumn{2}{l}{ Mean grade of conjunctivochalasis } & \multicolumn{2}{l|}{ Total conjunctivochalasis score } \\
\hline & $r$ & $p$ & $r$ & $p$ \\
\hline Age & 0.349 & 0.043 & 0.322 & 0.046 \\
\hline TBUT & -0.254 & 0.093 & -0.259 & 0.081 \\
\hline Schirmer test & -0.054 & 0.674 & -0.049 & 0.745 \\
\hline OSDI score & 0.252 & 0.112 & 0.248 & 0.134 \\
\hline CCT & 0.173 & 0.256 & 0.186 & 0.175 \\
\hline Keratometry & 0.069 & 0.613 & 0.143 & 0.402 \\
\hline AL & -0.208 & 0.165 & -0.181 & 0.224 \\
\hline ACD & 0.075 & 0.592 & 0.071 & 0.605 \\
\hline LT & -0.060 & 0.629 & -0.113 & 0.562 \\
\hline IOP & 0.078 & 0.583 & 0.066 & 0.617 \\
\hline TBUT: Tear-film break-up time, OSDI: Ocular surface disease index, CCT: Central corneal thickness, AL: Axial & \\
\hline lenght, ACD: Anterior chamber depth, LT: Lens thickness, IOP: Intraocular pressure. & \\
\hline r: Pearson correlation coefficient, p<0.05 statistically significant. & & \\
\hline
\end{tabular}


Table 4

Correlations between clinical characteristics with the mean grade of conjunctivochalasis and the total conjunctivochalasis score in group- 2 .

\begin{tabular}{|lllll|}
\hline \multicolumn{4}{r}{ Mean grade of conjunctivochalasis } & \multicolumn{2}{l|}{ Total conjunctivochalasis score } \\
\hline & $r$ & $p$ & $r$ & $p$ \\
\hline Age & 0.403 & 0.022 & 0.372 & 0.031 \\
\hline TBUT & -0.370 & 0.034 & -0.401 & 0.025 \\
\hline Schirmer test & -0.080 & 0.582 & -0.068 & 0.624 \\
\hline OSDI score & 0.338 & 0.045 & 0.362 & 0.040 \\
\hline CCT & 0.261 & 0.074 & 0.250 & 0.128 \\
\hline Keratometry & 0.132 & 0.441 & 0.083 & 0.579 \\
\hline AL & -0.213 & 0.142 & -0.267 & 0.068 \\
\hline ACD & 0.092 & 0.574 & 0.125 & 0.542 \\
\hline LT & -0.168 & 0.305 & -0.149 & 0.367 \\
\hline IOP & 0.138 & 0.424 & 0.130 & 0.483 \\
\hline TBUT: Tear-film break-up time, OSDI: Ocular surface disease index, CCT: Central corneal thickness, AL: Axial & \\
\hline lenght, ACD: Anterior chamber depth, LT: Lens thickness, IOP: Intraocular pressure. & \\
\hline r: Pearson correlation coefficient, $p<0.05$ statistically significant. & & \\
\hline
\end{tabular}

\section{Discussion}

Both the aging effect and the similarity in etiopathogenesis may increase the probability of the coexistence of conjunctivochalasis and PES in the same individual with aging [1-4, 10-17]. Kocabeyoglu et al. investigated the conjunctivochalasis in cases with PES, and the authors found that $56.6 \%$ of cases with PES had the conjunctivochalasis. They also stated that conjunctivochalasis was significantly seen more frequently in cases with PES compared to those without PES [14]. In our study, PES was detected in $42.1 \%$ of all conjunctivochalasis cases. To the best of our knowledge, the possible effects of the coexistence of these two diseases on OS and anterior segment structures were evaluated comprehensively for the first time with our study. TBUT, Schirmer test and OSDI questionnaire can be used in the diagnosis of OS disease. In literature, TBUT was found to be significantly shorter in patients with conjunctivochalasis compared to healthy individuals $[22,23]$. Inadequate distribution of the tear film on OS was considered to decrease the TBUT in conjunctivochalasis cases $[1,22]$. Similarly, TBUTs of individuals with PES were reported to be significantly lower than those of normal individuals $[24,25]$. This reduction was associated with destabilization of the tear film in PES cases [24]. In our study, both group-1 and group-2 had significantly shorter TBUT compared to healthy cases (group-3). Additionally, TBUT was even shorter in group-2 compared to group-1. According to these findings, we thought that the presence of PES in conjunctivochalasis cases might further decrease the TBUT value. 
In studies, Schirmer test values of conjunctivochalasis cases were stated to be similar to those of healthy individuals $[22,23]$. Ozek et al. determined that conjunctivochalasis impaired the tear distribution but it did not affect the tear amount [22]. On the other hand, Schirmer test value was detected to be significantly lower in cases with PES compared to healthy individuals $[24,25]$. However, in our study there were no significant differences among the three groups in terms of Schirmer test value. This may be due to the fact that the conjunctival folds existing in both group-1 and group-2 might cause the delayed tear clearance by impeding the tear flow or mechanically occluding the punctum [1, 22]. We considered that delayed tear clearance might also mask the negative effect of PES on Schirmer test in group-2. Therefore, TBUT test may be more important than the Schirmer test in the diagnosis of OS disease in cases with conjunctivochalasis [22]. In literature, OSDI score was found to be significantly higher in conjunctivochalasis cases compared to healthy individuals [22, 26]. Kocabeyoglu et al. reported a significantly greater OSDI score in patients with PES compared to healthy cases [14]. In our study, both group-1 and group-2 had significantly higher OSDI score compared to healthy cases (group-3). In addition, OSDI score was even greater in group-2 compared to group-1. According to these findings, we thought that the presence of PES in conjunctivochalasis cases might further increase the dry eye complaints. As far as we know, the relationships of conjunctivochalasis with anterior segment parameters except for the AL [27] had not been investigated until our study. Mimura et al. evaluated the relationship between the AL and conjunctivochalasis. The authors stated that conjunctivochalasis was seen more frequently in individuals with short AL [27]. It was shown that the AL [18] and ACD [28] of cases with PES were similar to those of healthy individuals. Conflicting results had been reported regarding the effect of PES on CCT. In different studies, it was detected that CCT was thinner [29] or thicker [30] in eyes with PES compared to the control group. However, in literature PES was reported to have mostly no effect on CCT [18, 28, 31]. To our knowledge, there was also no study evaluating the effects of coexistence of conjunctivochalasis and PES on anterior segment structures. In our study, CCTs, keratometry values, ALs, ACDs and LTs were similar in all groups.

In a community-based epidemiologic study, $53.52 \%$ of conjunctivochalasis eyes were reported as grade-1, $36.72 \%$ as grade-2, and $9.19 \%$ as grade-3 conjunctivochalasis [16]. In our study, cases with only conjunctivochalasis had $45.2 \%$ grade- $1,37.1 \%$ grade- 2 and $17.7 \%$ grade-3 conjunctivochalasis. In contrast, in cases with conjunctivochalasis accompanied by PES, the rates were $17.8 \%$ for grade- $1,35.5 \%$ for grade- 2 , and $46.7 \%$ for grade-3. We also found that in group-1, grade-1 conjunctivochalasis was significantly more frequent than grade-3 conjunctivochalasis, while in group-2, grade-3 conjunctivochalasis was significantly more frequent than grade-1 conjunctivochalasis. In intergroup comparison, compared to group-1, group-2 had significantly lower grade-1 conjunctivochalasis rate, higher grade-3 conjunctivochalasis rate, greater MGC, and higher TCS. Additionally, in the presence of PES in conjunctivochalasis cases, as both MGC and TCS increased, TBUT decreased and OSDI score increased. According to these results, we thought that the presence of PES in conjunctivochalasis cases might increase the conjunctivochalasis grade, and might worsen both the conjunctivochalasis findings and the dry eye related findings. However, we detected that the presence of PES might not affect the distributions of conjunctivochalasis locations. In literature, the number and height of conjunctival folds and the severity of conjunctivochalasis were stated to increase with aging $[15,16,32]$. Similarly, we determined that in group-1 and group-2, as age increased, both MGC and TCS increased. Marmalidou et al. hypothesized that with aging, a decrease in subconjunctival connective tissue might occur similar to aged skin, and this tissue change might cause the conjunctival laxity by disrupting the adhesion of the bulbar conjunctiva to the sclera. The authors also considered that this conjunctival laxity might induce the inflammation by leading to chronic mechanical friction, and eventually the conjunctivochalasis might develop or

Page $11 / 16$ 
progress in a vicious cycle containing the conjunctival laxity, mechanical friction, inflammation, and disruption of extracellular matrix [1].

This study had some limitations. The first limitation was that the levels of inflammatory mediators on OS could not be measured in cases. The second limitation was that the number of cases was relatively small. There might be other undetectable additional factors affecting the ocular structures. In the future, prospective followup studies with large case numbers can be planned. Despite of these limitations, we believed that this study could provide valuable informations about the effects of conjunctivochalasis accompanied by PES on OS and anterior segment structures. In summary, we found that conjunctivochalasis might cause the OS disease, while the presence of PES in conjunctivochalasis cases might increase the conjunctivochalasis grade, and might worsen both the OS disease and the conjunctivochalasis findings.

Figure 1. Modified grading and scoring system for conjunctivochalasis.

Table 1. Conjunctivochalasis characteristics of the group-1 and group-2.

Table 2. Clinical and ocular parameters of the groups.

Table 3. Correlations between clinical characteristics with the mean grade of conjunctivochalasis and the total conjunctivochalasis score in group-1.

Table 4. Correlations between clinical characteristics with the mean grade of conjunctivochalasis and the total conjunctivochalasis score in group-2.

\section{Declarations}

\section{Consent to participate and consent to publish}

Informed consent was obtained from all individual participants included in the study.

Written informed consent was obtained from the parents.

Ethical approval: All procedures performed in studies involving human participants were in accordance with the ethical standards of the institutional and/or national research committee and with the 1964 Helsinki Declaration and its later amendments or comparable ethical standards. This study was performed with approval of Izmir Tepecik Training and Research Hospital's Medical Research Ethical Committee (approval number: 2020/10-10) and in line with ethical principles of the Declaration of Helsinki.

No funds, grants, or other support was received.

Conflict of interest: The authors report no conflicts of interest.

All authors contributed to the study conception and design. Material preparation, data collection and analysis were performed by [Bediz Özen] and [Hakan Öztürk]. The first draft of the manuscript was written by [Bediz Özen] and all authors commented on previous versions of the manuscript. All authors read and approved the final manuscript. 


\section{References}

1. Marmalidou A, Kheirkhah A, Dana R (2018) Conjunctivochalasis: a systematic review. Surv Ophthalmol 63(4):554-564. doi: 10.1016/j.survophthal.2017.10.010

2. Gan JY, Li QS, Zhang ZY, Zhang W, Zhang XR (2017) The role of elastic fibers in pathogenesis of conjunctivochalasis. Int J Ophthalmol 10(9):1465-1473. doi: 10.18240/ijo.2017.09.21

3. Meller D, Li DQ, Tseng SC (2000) Regulation of collagenase, stromelysin, and gelatinase B in human conjunctival and conjunctivochalasis fibroblasts by interleukin-1beta and tumor necrosis factor-alpha. Invest Ophthalmol Vis Sci 41(10):2922-2929

4. Xiang MH, Zhang XR, Zhang ZY, Li QS, Wang HM, Han ZM, Zhou HM, Jia YL, Chen XX (2017) Expressions of matrix metalloproteinases 1 and 3 and their tissue inhibitors in the conjunctival tissue and fibroblasts cultured from conjunctivochalasis. Int J Ophthalmol 10(4):555-559. doi: 10.18240/ijo.2017.04.09

5. Meller D, Tseng SC (1998) Conjunctivochalasis: literature review and possible pathophysiology. Surv Ophthalmol 43(3):225-232. doi: 10.1016/s0039-6257(98)00037-x

6. Li DQ, Meller D, Liu Y, Tseng SC (2000) Overexpression of MMP-1 and MMP-3 by cultured conjunctivochalasis fibroblasts. Invest Ophthalmol Vis Sci 41(2):404-410

7. Acera A, Vecino E, Duran JA (2013) Tear MMP-9 levels as a marker of ocular surface inflammation in conjunctivochalasis. Invest Ophthalmol Vis Sci 54(13):8285-8291. doi: 10.1167/iovs.13-12235

8. Schlötzer-Schrehardt U, Naumann GO (2006) Ocular and systemic pseudoexfoliation syndrome. Am J Ophthalmol 141(5):921-937. doi: 10.1016/j.ajo.2006.01.047

9. Ghaffari Sharaf M, Amidian S, Rathod V, Crichton A, Damji KF, Wille H, Unsworth LD (2020) Structural polymorphisms in fibrillar aggregates associated with exfoliation syndrome. Sci RepSep 10(1):15860. doi: 10.1038/s41598-020-72737-6

10. Yildirim Z, Yildirim F, Uçgun NI, Sepici-Dinçel A (2013) The role of the cytokines in the pathogenesis of pseudoexfoliation syndrome. Int J Ophthalmol 6(1):50-53. doi: 10.3980/j.issn.2222-3959.2013.01.10

11. SarenacVulovic T, Pavlovic S, Lutovac M, Zdravkovic V, Sreckovic S, Zdravkovic N (2019) Regulatory cytokines prescribe the outcome of the inflammation in the process of pseudoexfoliation production. $J$ Chin Med Assoc 82(12):935-940. doi: 10.1097/JCMA.0000000000000214

12. Zenkel M, Lewczuk P, Jünemann A, Kruse FE, Naumann GO, Schlötzer-Schrehardt U (2010) Proinflammatory cytokines are involved in the initiation of the abnormal matrix process in pseudoexfoliation syndrome/glaucoma. Am J Pathol 176(6):2868-2879. doi: 10.2353/ajpath.2010.090914

13. Schlötzer-Schrehardt U, Lommatzsch J, Küchle M, Konstas AG, Naumann GO (2003) Matrix metalloproteinases and their inhibitors in aqueous humor of patients with pseudoexfoliation syndrome/glaucoma and primary open-angle glaucoma. Invest Ophthalmol Vis Sci 44(3):1117-1125. doi: 10.1167/iovs.02-0365

14. Kocabeyoğlu S, Irkeç M, Orhan M, Mocan MC (2012) Evaluation of the ocular surface parameters in pseudoexfoliation syndrome and conjunctivochalasis. Turk J Ophthalmol 42(5):332-335. doi. 10.4274/tjo.42.392000

15. Mimura T, Yamagami S, Usui T, Funatsu H, Mimura Y, Noma H, Honda N, Amano S (2009) Changes of conjunctivochalasis with age in a hospital-based study. Am J Ophthalmol 147(1):171-177e1. doi: 
10.1016/j.ajo.2008.07.010

16. Zhang X, Li Q, Zou H, Peng J, Shi C, Zhou H, Zhang G, Xiang M, Li Y (2011) Assessing the severity of conjunctivochalasis in a senile population: a community-based epidemiology study in Shanghai, China. BMC Public Health 11:198. doi: 10.1186/1471-2458-11-198

17. You QS, Xu L, Wang YX, Yang H, Ma K, Li JJ, Zhang L, Jonas JB (2013) Pseudoexfoliation: normative data and associations: the Beijing eye study 2011. Ophthalmology 120(8):1551-1558. doi: 10.1016/j.ophtha.2013.01.020

18. Moghimi S, Mazloumi M, Johari MK, Fard MA, Chen R, Weinreb R, Nouri-Mahdavi K (2017) Comparison of macular choroidal thickness in patients with pseudoexfoliation syndrome to normal control subjects with enhanced depth SD-OCT imaging. J Curr Ophthalmol 29(4):258-263. doi: 10.1016/j.joco.2017.06.009

19. Mimura T, lida M, Oshima R, Noma H, Kamei Y, Goto M, Kondo A, Matsubara M (2017) Changes of conjunctivochalasis after cataract surgery via a superior transconjunctival sclerocorneal incision. Int Ophthalmol 37(3):691-700. doi: 10.1007/s10792-016-0328-y

20. Mimura T, Usui T, Yamagami S, Funatsu H, Noma H, Toyono T, Mori M, Amano S (2011) Relationship between conjunctivochalasis and refractive error. Eye Contact Lens 37(2):71-78. doi:

10.1097/ICL.0b013e31820ca377

21. Wolffsohn JS, Arita R, Chalmers R, Djalilian A, Dogru M, Dumbleton K, Gupta PK, Karpecki P, Lazreg S, Pult H, Sullivan BD, Tomlinson A, Tong L, Villani E, Yoon KC, Jones L, Craig JP (2017) TFOS DEWS II Diagnostic Methodology report. Ocul Surf 15(3):539-574. doi: 10.1016/j.jtos.2017.05.001

22. Ozek D, Karaca EE, Evren Kemer O (2020) The effect of conjunctivochalasis detected by anterior segment optical coherence tomography on tear function in an elderly population. Ther Adv Ophthalmol 12:2515841420930876. doi: 10.1177/2515841420930876

23. Wang Y, Dogru M, Matsumoto Y, Ward SK, Ayako I, Hu Y, Okada N, Ogawa Y, Shimazaki J, Tsubota K (2007) The impact of nasal conjunctivochalasis on tear functions and ocular surface findings. Am J Ophthalmol 144(6):930-937. doi: 10.1016/j.ajo.2007.07.037

24. Noori S, Sati A, Moulick PS, Kaushik J, Shankar S, Bose R (2020) Tear film abnormalities in pseudoexfoliation syndrome and normal healthy participants: A comparative analysis. Med J Armed Forces India 76(3):303-306. doi: 10.1016/j.mjafi.2019.01.003

25. Kozobolis VP, Christodoulakis EV, Naoumidi II, Siganos CS, Detorakis ET, Pallikaris LG (2004) Study of conjunctival goblet cell morphology and tear film stability in pseudoexfoliation syndrome. Graefes Arch Clin Exp Ophthalmol 242(6):478-483. doi: 10.1007/s00417-004-0865-3

26. Le Q, Cui X, Xiang J, Ge L, Gong L, Xu J (2014) Impact of conjunctivochalasis on visual quality of life: a community population survey. PLoS ONE 9(10):e110821. doi: 10.1371/journal.pone.0110821

27. Mimura T, Yamagami S, Kamei Y, Goto M, Matsubara M (2013) Influence of axial length on conjunctivochalasis. Cornea 32(8):1126-1130. doi: 10.1097/IC0.0b013e318292b7a2

28. Doganay S, Tasar A, Cankaya C, Firat PG, Yologlu S (2012) Evaluation of Pentacam-Scheimpflug imaging of anterior segment parameters in patients with pseudoexfoliation syndrome and pseudoexfoliative glaucoma. Clin Exp Optom 95(2):218-222. doi: 10.1111/j.1444-0938.2011.00691.x

29. Inoue K, Okugawa K, Oshika T, Amano S (2003) Morphological study of corneal endothelium and corneal thickness in pseudoexfoliation syndrome. Jpn J Ophthalmol 47(3):235-239. doi: 10.1016/s0021-

Page $14 / 16$ 
5155(03)00022-4

30. Puska P, Vasara K, Harju M, Setälä K (2000) Corneal thickness and corneal endothelium in normotensive subjects with unilateral exfoliation syndrome. Graefes Arch Clin Exp Ophthalmol 238(8):659-663. doi:

$10.1007 /$ s004170000159

31. Palko JR, Qi O, Sheybani A (2017) Corneal Alterations Associated with Pseudoexfoliation Syndrome and Glaucoma: A Literature Review. J Ophthalmic Vis Res 12(3):312-324. doi: 10.4103/jovr.jovr_28_17

32. Gumus K, Pflugfelder SC (2013) Increasing prevalence and severity of conjunctivochalasis with aging detected by anterior segment optical coherence tomography. Am J Ophthalmol 155(2):238-242e2. doi: 10.1016/j.ajo.2012.07.014

\section{Figures}

Number of conjunctival folds and relationship to the tear meniscus height

Grade (0): No persistent fold

Grade (1): Single, small fold

Grade (2): Two or more folds and not higher than the tear meniscus

Grade (3): Multipl folds and higher than the tear meniscus

Location of conjunctival folds

(N): Nasal

(T): Temporal

(M): Middle (or inferior to the limbus)

Extent of conjunctival folds

E (0): None

E (1): At one location

E (2): At two locations

E (3): Affecting the whole eyelid

Changes provoked with downward gaze (DG)

DG (0): No difference

DG (1): Height or extent of conjunctivochalasis increases

Changes provoked with digital pressure (DP)

DP (0): No difference

DP (1): Height or extent of conjunctivochalasis increases

Superficial punctate staining (SPS) at the lower eyelid margin

SPS (0): Absent

SPS (1): Present

\section{Figure 1}

Modified grading and scoring system for conjunctivochalasis (Reference numbers: 19 and 20). 
Page 16/16 